\title{
nature
}

\section{Researchers:show world leaders how to behave in a crisis}

\section{Scientists are dropping everything to team up and fight COVID-19. Presidents and prime ministers should, too.}

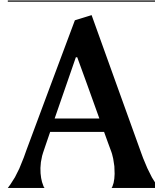

Ithough the coronavirus pandemic has become a threat to every country on Earth, world leaders are all at sea - showing few signs that they wish to cooperate genuinely to combat it. By contrast, tens of thousands of researchers from different disciplines and countries have joined research and public-health efforts to fight COVID-19 (see page 13). They are working across continents, lending their time, ideas, expertise, equipment and money to the emergency public-health effort. They are providing virus testing facilities; donating personal protective equipment; designing and manufacturing ventilators and other breathing apparatus. And when it comes to the research effort itself, thousands of volunteers from all over the world are enthusiastically signing up to say they are available to do what they can.

University-based laboratories such as those at the Broad Institute of MIT and Harvard in Cambridge, Massachusetts, and at the National University of Colombia in Bogotá, are carrying out COVID-19 tests. That said, more universities with medical schools need to provide access to virus testing facilities.

The emergency response to the pandemic is also creating new types of collaboration. For example, researchers and clinicians in the United Kingdom, China and Italy have been working at speed with engineers from Formula 1 motor racing. In the space of a week, they have managed to reverse-engineer a device that helps people with serious lung infections to breathe more easily.

The breathing aid uses a method known as continuous positive airway pressure. It works by supplying people experiencing breathing difficulties with relatively small but continuous amounts of air, and it has the potential to reduce the numbers of people needing ventilators in hospitals. We urge the project's partners to publish and share their designs so that the device can be tested globally, and so that it can eventually be made available to health authorities in low- and middle-income countries.

The COVID-19 research effort also got a welcome boost. Researchers from around the world have set up an online platform for those who want to volunteer for research-related tasks. The platform, Crowdfight COVID19 , matches volunteers to researchers who have specific tasks or needs - anything from transcribing data from notebooks and searching the literature, to providing specific expertise. As this editorial went to press, Crowdfight

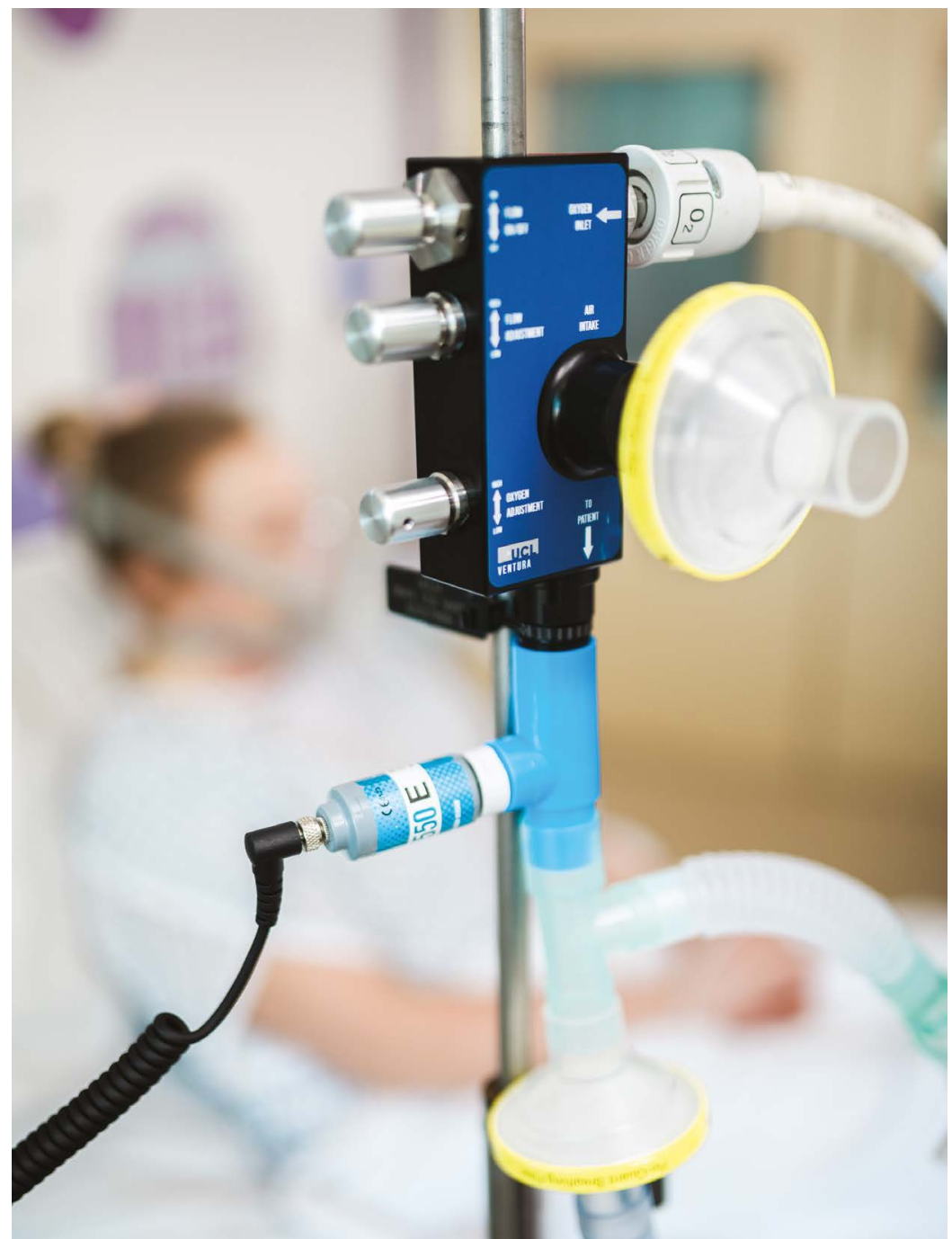

Clinicians and automotive engineers are jointly developing breathing aids.

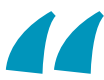

It is only a matter of time before world leaders will have to step up."
COVID-19 had attracted more than 35,000 volunteers.

These efforts are important because world leaders need to see that international coordination on COVID-19 is thriving. Presidents and prime ministers are moving too slowly, in stark contrast to their response to the financial crisis of 2008, when heads of government, ministries of finance, central banks and other multilateral lending agencies got together and agreed what needed to be done.

Although different funding agencies are collaborating on coronavirus research, there is less consensus at the highest levels of government, and most countries seem to be making independent decisions about how to protect their citizens.

As infections and deaths continue to rise, it is only a matter of time before world leaders will have to step up. They have no choice, because there's little point in extinguishing the virus in one country when it's exploding elsewhere. A genuinely global response is needed - and world leaders must follow the fine example being set by researchers. 